\title{
Strength assessment during shallow penetration of a sphere in clay
}

\author{
J. P. MORTON*, C. D. O’LOUGHLIN* and D. J. WHITE*
}

\begin{abstract}
Strength interpretation from the measured penetration resistance of full-flow penetrometers, such as the T-bar and ball, is generally based on a constant bearing capacity factor associated with a deep flow-round mechanism. This approach may underestimate the strength of near-surface sediments, which is becoming increasingly important for the design of offshore infrastructure such as pipelines, steel catenary risers and mudmats. This paper describes a series of centrifuge experiments designed to capture the change in the capacity factor of a ball penetrometer during shallow penetration. A rigorous consideration of soil buoyancy is provided. This is an important consideration in soils with a higher strength to self-weight ratio because a cavity is formed by the passage of the ball and remains open to greater depths. The depth at which a full-flow mechanism develops is related to the dimensionless strength ratio, expressed as the ratio of the undrained shear strength to the effective unit weight and penetrometer diameter. This observation forms the basis for proposed formulations that describe the evolution of the bearing capacity factor with depth for different dimensionless strength ratios. These formulations can be used to determine more accurately the undrained shear strength of near-surface soil over the range of dimensionless strength ratios that is of interest to offshore applications.
\end{abstract}

KEYWORDS: bearing capacity; centrifuge modelling; penetrometers; shear strength; site investigation

ICE Publishing: all rights reserved

\section{NOTATION}

$\begin{array}{ll}A_{\mathrm{p}} & \text { projected area of the sphere } \\ A_{\mathrm{s}} & \text { shaft area } \\ c_{\mathrm{v}} & \text { coefficient of vertical consolidation } \\ D & \text { diameter of penetrometer } \\ F_{\text {buoy }} & \text { soil buoyancy } \\ F_{\mathrm{s}} & \text { evolving soil resistance } \\ H_{\mathrm{c}} & \text { cavity depth } \\ k & \text { undrained shear strength gradient } \\ m & \text { plastic volumetric strain ratio } \\ N_{\mathrm{b}} & \text { bearing capacity factor } \\ N_{\mathrm{b}-\text { deep }} & \text { deep bearing capacity factor } \\ N_{\mathrm{b}-\text { shallow }} & \text { shallow bearing capacity factor } \\ q_{\mathrm{b}} & \text { buoyancy resistance } \\ q_{\mathrm{m}} & \text { measured bearing pressure } \\ q_{\mathrm{net}} & \text { net penetration resistance } \\ Q_{\mathrm{s}} & \text { soil resistance } \\ S_{\mathrm{u}} & \text { undrained shear strength } \\ u_{0} & \text { hydrostatic pore pressure } \\ v & \text { penetration rate } \\ w & \text { ball invert depth } \\ \hat{w}_{\mathrm{op}} & \text { normalised operative depth } \\ \alpha & \text { net area ratio of the load cell core to the shaft area } \\ \gamma^{\prime} & \text { effective unit weight of the soil } \\ \sigma_{\mathrm{v}} & \text { overburden pressure } \\ \sigma_{\mathrm{v}}^{\prime} & \text { vertical effective stress }\end{array}$

\section{INTRODUCTION}

For a deeply embedded ball penetrometer, a full-flow mechanism that is symmetrical above and below the ball is operative and the undrained shear strength, $s_{\mathrm{u}}$, can be interpreted from the measured bearing pressure, $q_{\mathrm{m}}$,

Manuscript received 4 July 2014; first decision 6 August 2014; accepted 5 September 2014.

Published online at www.geotechniqueletters.com on 10 October 2014.

${ }^{*}$ Centre for Offshore Foundation Systems, University of Western Australia, Perth, WA, Australia according to $s_{\mathrm{u}}=q_{\mathrm{m}} / N_{\mathrm{b} \text {-deep. }}$. However, at shallow penetration depths, a full-flow mechanism does not develop and $s_{\mathrm{u}}$ should be interpreted from the measured penetration resistance using a bearing capacity factor $N_{\text {b-shallow }}<N_{\text {b-deep }}$. Adopting an appropriate $N_{\text {b-shallow, and accounting for its }}$ evolution to $N_{\text {b-deep }}$ with depth, is an important aspect of quantifying $s_{\mathrm{u}}$ over the upper $1-2 \mathrm{~m}$ of the seabed. This is critical for the design of almost all shallowly embedded offshore infrastructure (Puech et al., 2010) including subsea pipelines, steel catenary risers and mudmats.

Large-deformation finite-element (LDFE) analyses on a T-bar (White et al., 2010; Tho et al., 2012), spudcan (Hossain et al., 2005) and ball penetrometer (Zhou et al., 2013) have shown that the transition depth from $N_{\text {b-shallow }}$ to $N_{\text {b-deep }}$ is dependent on the dimensionless strength ratio $s_{\mathrm{u}} / \gamma^{\prime} D$, where $\gamma^{\prime}$ is the effective unit weight of the soil and $D$ is the diameter of the penetrometer. Higher strength ratios are associated with a delay in the transition to a steady $N_{\text {b-deep. }}$. Correlations for the transition depth and $N_{\text {b-shallow }}$ have been derived and, in the case of the T-bar and ball, a basis for correcting penetration data within the shallow zone has been proposed (White et al., 2010; Zhou et al., 2013). However, from the perspective of a spherical penetrometer, which is the focus of this paper, the range of strength ratios previously examined $\left(s_{\mathrm{u}} / \gamma^{\prime} D=2 \cdot 95-44 \cdot 25\right.$ (Zhou et al., 2013)) is narrower than the range that is of practical interest for offshore problems. For example, a $250 \mathrm{~mm}$ diameter freefall spherical penetrometer (for measuring the strength of the seabed (Morton \& O'Loughlin, 2012)) penetrating very soft soil is associated with low values of $s_{\mathrm{u}} / \gamma^{\prime} D$ approaching $0 \cdot 1$ at one diameter embedment, whereas an $80 \mathrm{~mm}$ piezoball penetrating the seabed with a crust strength of $\approx 20 \mathrm{kPa}$ is associated with high values of $s_{\mathrm{u}} / \gamma^{\prime} D$, approaching 40 .

The motivation for this study was to experimentally

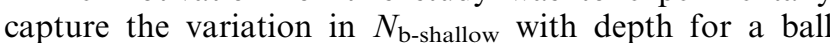
penetrometer embedding into clay over a wide range of $s_{\mathrm{u}} / \gamma^{\prime} D$. The experimental data are combined with reinterpreted 
LDFE results (Zhou et al., 2013) and form the basis of a new correlation that describes the evolution of $N_{\mathrm{b}}$ with depth.

\section{EXPERIMENTAL DETAILS}

The problem is addressed through centrifuge tests carried out at $100 \mathrm{~g}$ in the University of Western Australia (UWA) beam centrifuge. The penetration resistance response and the degree of hole-closure were analysed for nine penetrometer tests using a $11.3 \mathrm{~mm}$ diameter ball with a $4.8 \mathrm{~mm}$ diameter shaft, penetrating a kaolin clay sample with a progressively higher overconsolidation ratio (OCR). A constant penetration rate of $1 \mathrm{~mm} / \mathrm{s}$ was adopted such that the non-dimensional velocity $v D / c_{\mathrm{v}} \approx 130$ ( $v$ is the penetration rate, $D$ is the sphere diameter and $c_{\mathrm{v}}$ is the coefficient of vertical consolidation $\approx 2.8 \mathrm{~m}^{2} /$ year (Cocjin et al., 2014)) and the response is primarily undrained (House et al., 2001). A video recording observed the progressive hole-closure during each test and provided a means of determining the depth at which the cavity, formed by the passage of the ball, closed over. The experimental arrangement is shown in Fig. 1.

\section{EXPERIMENTAL PROCEDURE \\ Preparation of clay specimen}

The sample was prepared by mixing kaolin powder with water in a vacuum mixer at a moisture content equal to twice the liquid limit $(120 \%)$. A drainage sand layer at the base of the sample allowed two-way drainage during self-weight consolidation in the centrifuge at $100 \mathrm{~g}$, and vertical drains in the corners of the sample ensured there was no hydraulic gradient over the height of the sample. A nominal $10 \mathrm{~mm}$ layer of free water was maintained throughout testing.

In order to investigate the range of $s_{\mathrm{u}} / \gamma^{\prime} D$ of interest (spanning two orders of magnitude), the local $s_{\mathrm{u}}$ was progressively increased by scraping a $20 \mathrm{~mm}$ layer of clay from the surface of the sample between each consecutive penetration test (see Fig. 2). This had the effect of increasing the OCR of the clay and increasing $s_{\mathrm{u}}$ relative to the (new) sample surface.

\section{Theoretical basis for interpretation of measured ball penetration resistance}

As the ball penetrates the soil, the measured bearing pressure $q_{\mathrm{m}}$ includes the evolving soil resistance $q_{\mathrm{s}}$, expressed in terms of $N_{\mathrm{b}}$, and the resistance due to soil buoyancy, $q_{\mathrm{b}}$

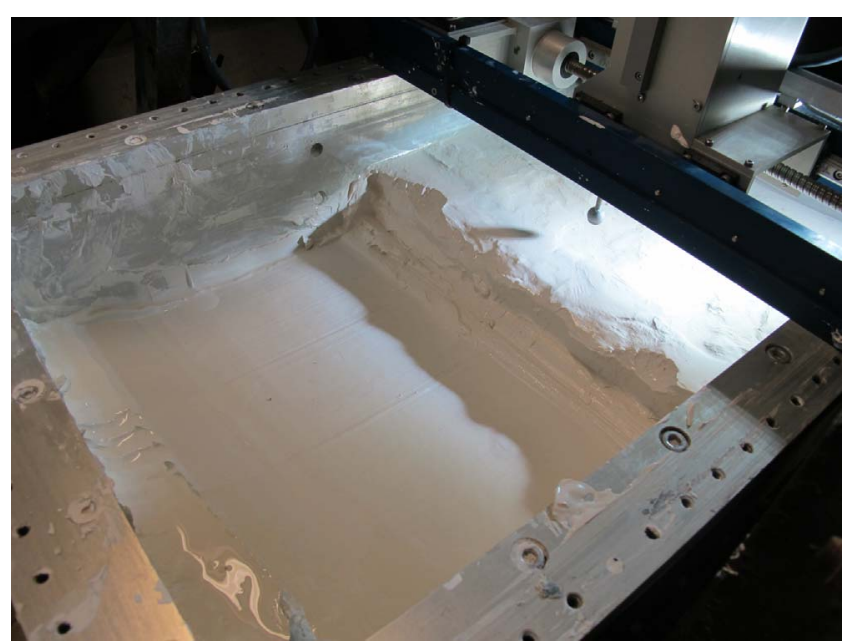

Fig. 2. A scraped soil sample before a test

$$
q_{\mathrm{m}}=q_{\mathrm{s}}+q_{\mathrm{b}}=N_{\mathrm{b}} s_{\mathrm{u}}+\frac{F_{\text {buoy }}}{A_{\mathrm{p}}}
$$

where $F_{\text {buoy }}$ is the soil buoyancy force and $A_{\mathrm{p}}$ is the projected area of the sphere.

If the ball is deeply embedded such that the soil flows around the ball during penetration, the buoyancy force can be calculated from Archimedes' principle; that is, the buoyancy force is the volume of the displaced soil multiplied by the effective unit weight of the soil, $F_{\text {buoy }}=$ $\left(\pi D^{3} / 6\right) \gamma^{\prime}$. However, during initial penetration, the soil does not flow around the ball. Instead, a cavity is created above the ball and the soil that would have filled this void is instead accommodated by heave at the soil surface.

To capture this heave effect, a simple multiplier can be applied on $F_{\text {buoy }}$, as proposed previously for the penetration of cylindrical and spherical geometries (e.g. Merifield et al., 2009; White et al., 2010; Chatterjee et al., 2012; Zhou et al., 2013). An alternative approach to derive this multiplier directly, is to consider the work required to lift the soil that is displaced by the incrementally advancing ball. This can be done by assuming a cavity geometry formed by the advancing ball, which is approximated here as an inverted cone for all considered values of $s_{\mathrm{u}} / \gamma^{\prime} D$, prompted by camera observations (e.g. see Fig. 3) and supported by LDFE simulations (Zhou et al., 2013).

At a ball invert depth of $w \leq 0 \cdot 5 D$ (Fig. 4(a)), all of the soil displaced by the advancing ball is lifted to the soil surface. The work done then becomes the weight of the
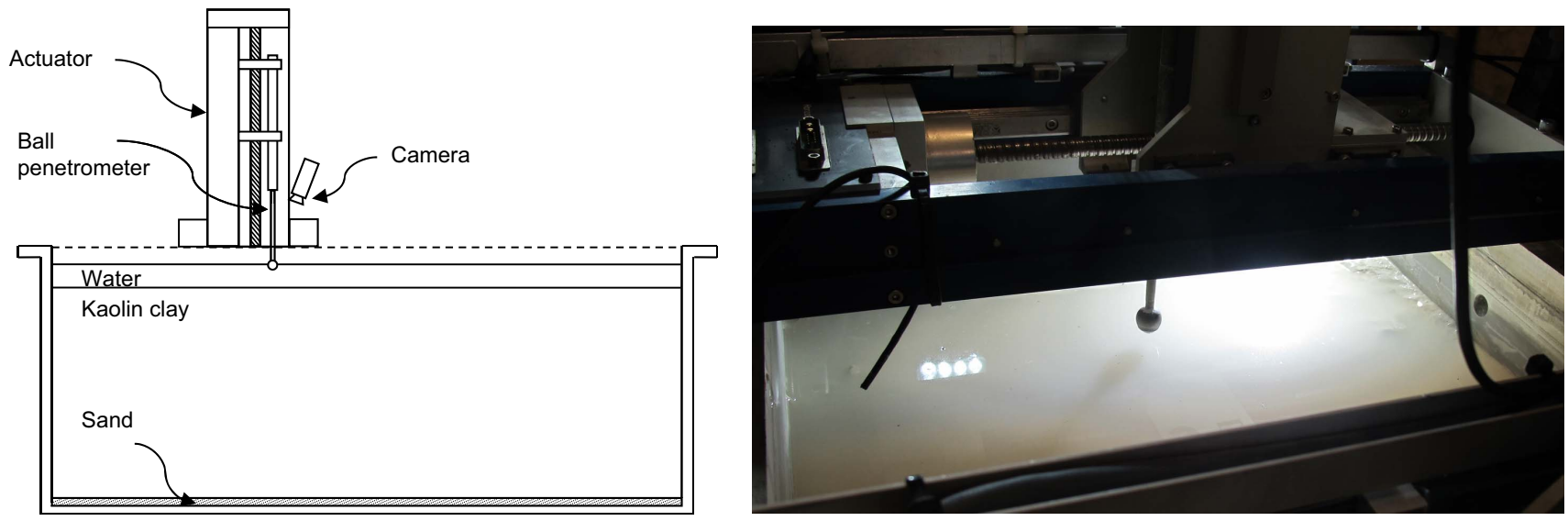

Fig. 1. Experimental arrangement in the beam centrifuge 


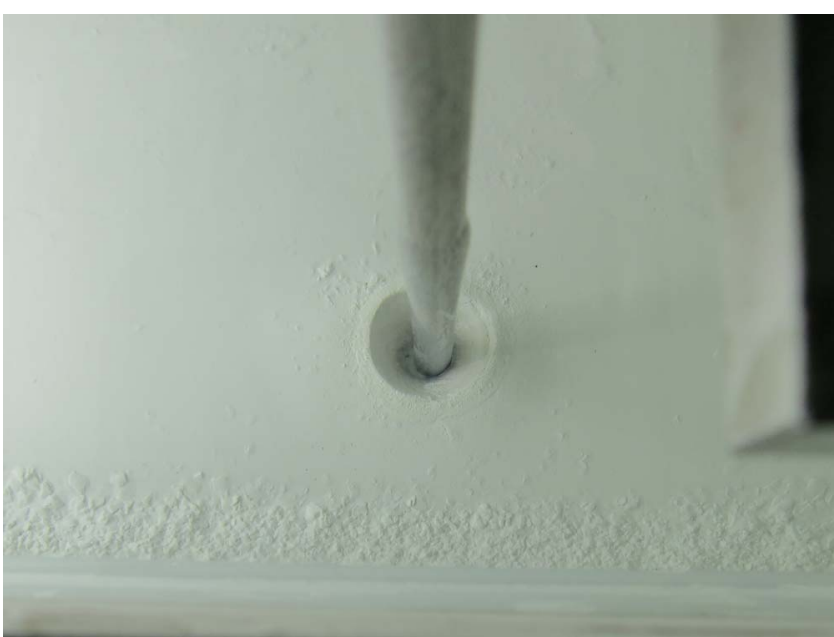

Fig. 3. Ball penetrometer and cavity after a penetration test

displaced soil multiplied by the distance between the centroidal height of the embedded ball (a spherical cap) and the soil surface. For $0 \cdot 5 D>w \leq H_{\mathrm{c}}+D$, where $H_{\mathrm{c}}$ is the cavity depth, only some of the soil displaced by the advancing ball is lifted to the surface. The remainder fills part of the cavity created by the increment of ball penetration, as shown in Fig. 4(b). In this case, the work done is calculated by adding the gain in potential energy by these two separate elements of soil, resulting in the profile of soil buoyancy with embedment given in Fig. 4(c).

The net penetration resistance $q_{\text {net }}$ can be calculated using the measured resistance $q_{\mathrm{m}}$ from equation (1) by correcting for the unequal pore pressure and overburden pressure effects due to the shaft behind the ball (Chung \& Randolph, 2004)

$$
q_{\mathrm{net}}=q_{\mathrm{m}}-\left[\sigma_{\mathrm{v}}-u_{0}(1-\alpha)\right] \frac{A_{\mathrm{s}}}{A_{\mathrm{p}}}
$$

where $\sigma_{\mathrm{v}}$ is the overburden pressure, $u_{0}$ is the hydrostatic pore pressure, $A_{\mathrm{s}}$ is the shaft area and the parameter $\alpha$ is the net area ratio of the load cell core to the shaft area $(\alpha=0.8$ for the tests considered here).

For a deeply embedded ball, $q_{\text {net }}-$ and hence the inferred $s_{u}$ - corresponds to the mid-height of the ball due to the depth symmetry of the flow-round mechanism. For a shallowly embedded ball, where the full-flow mechanism is not fully developed, the normalised operative depth $\hat{w}_{\text {op }}$ is assumed to vary linearly up to the depth where a full flowround mechanism occurs, in a similar manner to that

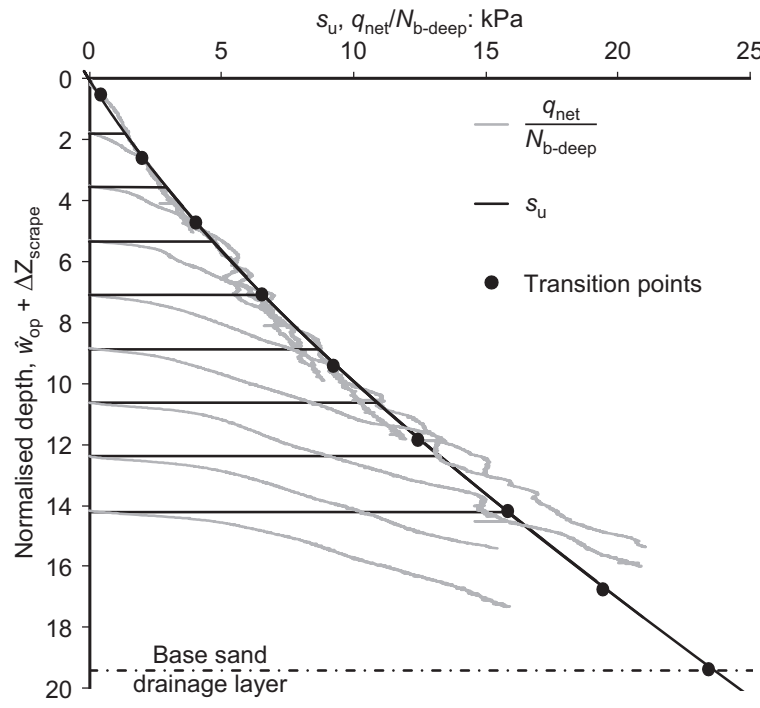

Fig. 5. Comparison of strength profiles of Ladd et al. (1977) and $q_{\text {net }} / N_{\text {b-deep }}$ profiles

proposed for a shallowly embedded T-bar (White et al., 2010)

$$
\hat{w}_{\mathrm{op}}=\frac{w}{D}-0 \cdot 5\left(\frac{w}{H_{\mathrm{c}}+D}\right) \geq \frac{w}{D}-0.5
$$

Omitted from the above theoretical framework is any consideration of how $N_{\mathrm{b}}$ evolves during shallow to deep penetration. This has been purposely excluded from the preceding discussion and will be formulated later in the paper to reflect the experimental results presented in the following section.

\section{RESULTS AND COMPARISONS In-flight video camera observations}

The camera was synchronised with the data acquisition system such that visual observations could be relayed to the measured penetration response. For lower values of $s_{\mathrm{u}} / \gamma^{\prime} D$, where the open cavity depth was lower and could be captured by the camera, the instances when soil flowed over the ball were consistent with the transitional depths inferred from the penetration profiles shown in Fig. 5 (and discussed in the next section). This observation is at variance with the LDFE results reported by Zhou et al. (2013), which indicate that more penetration is required to establish a deep failure mechanism after full flow of soil over the top of the ball.

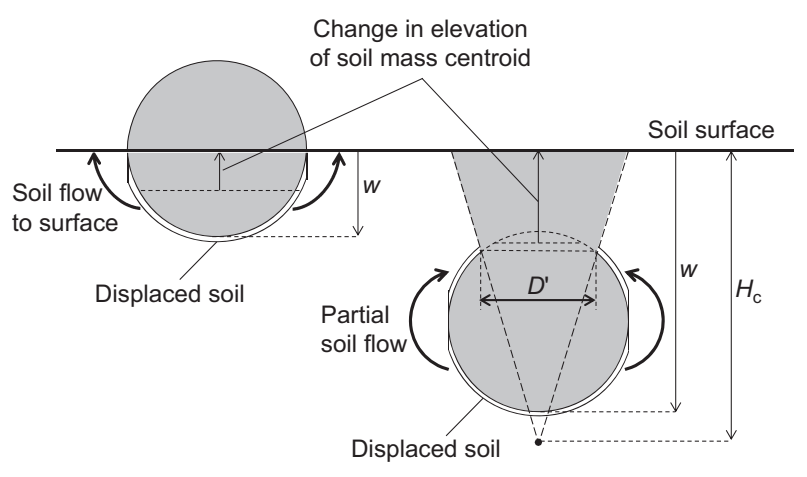

(a)

(b)

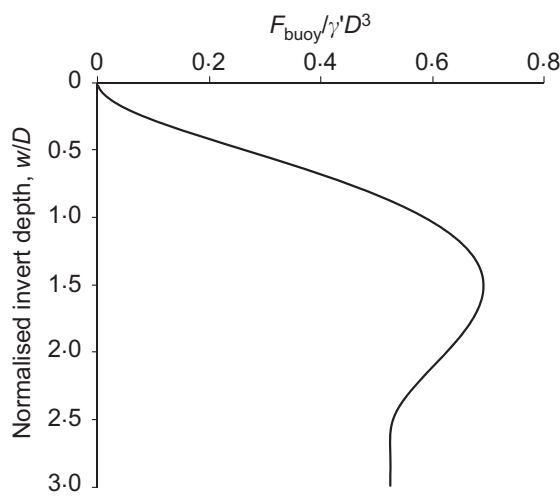

(c)

Fig. 4. Schematic illustration of soil buoyancy due to (a) the sphere and (b) the sphere and conical cavity. (c) Buoyancy function for a typical cavity depth 
During shallow penetration, little or no heave was observed on the soil surface, particularly for tests with higher values of $s_{\mathrm{u}} / \gamma^{\prime} D$. This is considered to be due to the axisymmetric flow mechanism of the ball, which reduces the heave compared with plane strain flow for a cylindrical T-bar or pipeline (Stanier \& White, 2014). In light of this observation, enhancement of $F_{\text {buoy }}$ in equation (1) to account for heave of the soil surface, as considered by Merifield et al. (2009), Randolph \& White (2008) and Stanier \& White (2014), was not included.

\section{Undrained shear strength profiles}

As discussed earlier, the OCR of the sample was incrementally increased by scraping an additional $20 \mathrm{~mm}$ from the sample surface between penetration tests. The strength of the sample can then be assumed to vary with depth according to equation (4), proposed by Ladd et al. (1977)

$$
s_{\mathrm{u}}=\sigma_{\mathrm{v}}^{\prime}\left(\frac{s_{\mathrm{u}}}{\sigma_{\mathrm{v}}^{\prime}}\right)_{\mathrm{nc}} \mathrm{OCR}^{m}
$$

where $\sigma_{\mathrm{v}}^{\prime}$ is the current vertical effective stress, determined from the $\gamma^{\prime}$ profile with depth and the varying acceleration level within the centrifuge ( $93 \boldsymbol{g}$ to $105 \mathrm{~g}$ over the depth of penetration), and $m$ is the plastic volumetric strain ratio (Schofield \& Wroth, 1968). The normally consolidated undrained strength ratio $\left(s_{\mathrm{u}} / \sigma_{\mathrm{v}}^{\prime}\right)_{\mathrm{nc}}=0 \cdot 13$, as determined from ball penetrometer tests before scraping the soil surface (i.e. OCR $=1$ ) using the commonly adopted $N_{\text {b-deep }}=10 \cdot 5$ (Chung $\&$ Randolph, 2004). The ratio $\left(s_{\mathrm{u}} / \sigma_{\mathrm{v}}^{\prime}\right)_{\mathrm{nc}}$ increases to $0 \cdot 15$ if the measured resistance (which ignores shaft effects) is considered, similar to $\left(s_{\mathrm{u}} / \sigma_{\mathrm{v}}^{\prime}\right)_{\mathrm{nc}}=0 \cdot 16$ reported by Richardson et al. (2009) and $\mathrm{Hu}$ et al. (2014), and equivalent to an undrained strength gradient with prototype depth, $k=1 \mathrm{kPa} / \mathrm{m}$, which is typical for UWA kaolin. The best agreement between equation (4) and the experimental $q_{\text {net }} / N_{\text {b-deep }}$ profiles in the overconsolidated samples was obtained using $m=1$ (rather than the commonly reported $m=0 \cdot 8$ ), which reflects the minimal swelling time permitted between each soil scrape and the subsequent penetration test.

\section{Deep mechanism transition depth}

The normalised transition depths $\hat{w}_{\text {deep-op }}$ are also shown in Fig. 5, and were selected as the depths where the $q_{\text {net }} / N_{\text {b-deep }}$ experimental data were judged to have reached $s_{\mathrm{u}}$ predicted using equation (4). The final two profiles do not reach the predicted $s_{\mathrm{u}}$ profile due to the proximity of the base drainage sand layer and $\hat{w}_{\text {deep-op }}$ are approximated in these instances on the basis of the $N_{\mathrm{b}}$ variation with depth, discussed later. Values of $\hat{w}_{\text {deep-op }}$ are also shown in Fig. 6 alongside previously reported T-bar (White et al., 2010), spudcan (Hossain et al., 2005) and ball (Zhou et al., 2013) data, but reinterpreted to account for the definition of operative depth adopted here. Further reinterpretation of the ball data of Zhou et al. (2013) was made to ascertain $\hat{w}_{\text {deep-op }}$ assessed as when $N_{\mathrm{b}}$ became effectively constant (to within $<5 \%$ of the final value) rather than reaching the limit, which is difficult to judge and is approached asymptotically. The experimental ball data reported here, together with the reinterpreted Zhou et al. (2013) ball data, now form a unique relationship between $\hat{w}_{\text {deep-op }}$ and $s_{\mathrm{u}} / \gamma^{\prime} D$ for a ball penetrometer (where $s_{\mathrm{u}}$ is the undrained strength at $\hat{w}_{\text {deep-op }}$ ), which can be described using

$$
\hat{w}_{\text {deep-op }}=a+\left(b \frac{s_{\mathrm{u}}}{\gamma^{\prime} D}\right)^{c}+\frac{d-a}{1+\left[\left(s_{\mathrm{u}} / \gamma^{\prime} D\right) / e\right]^{f}}
$$

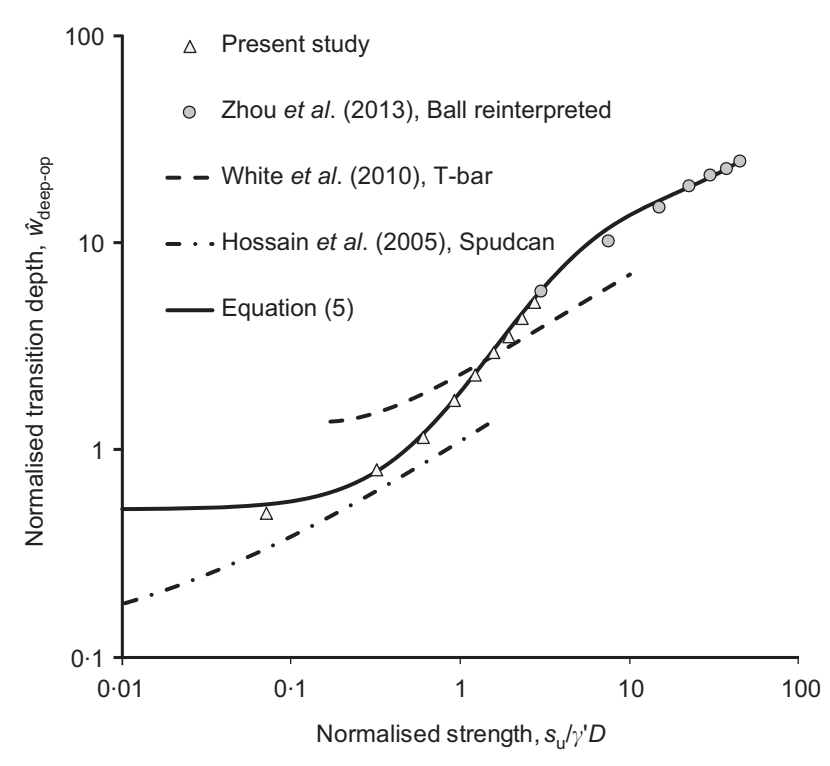

Fig. 6. Effect of strength ratio $s_{\mathrm{u}} / \gamma^{\prime} D$ on transition depth

where the fitting constants $a=16 \cdot 3, b=0 \cdot 12, c=1 \cdot 3$, $d=0.52, e=4.9$ and $f=1 \cdot 5$.

\section{Shallow bearing capacity factors}

Figure 7 shows the experimental variation in $N_{\mathrm{b}}$ with depth for each penetration test, obtained by dividing $q_{\text {net }}$ by $s_{\mathrm{u}}$ from equation (4). Each $N_{\mathrm{b}}$ profile follows the same trend, commencing at zero at the soil surface and reaching a steady $N_{\text {b-deep }}$ at the transition depth, which is entirely dependent on $s_{\mathrm{u}} / \gamma^{\prime} D$. This variation in $N_{\mathrm{b}}$ with depth can be fitted using equation (6) (also shown on Fig. 7)

$$
N_{\text {b-shallow }}=N_{\text {b-deep }}\left(\frac{\hat{w}_{\text {op }}}{\hat{w}_{\text {deep-op }}}\right)^{p}
$$

and

$$
p=0 \cdot 49\left(\frac{s_{\mathrm{u}}}{\gamma^{\prime} D}\right)^{-0 \cdot 01}
$$

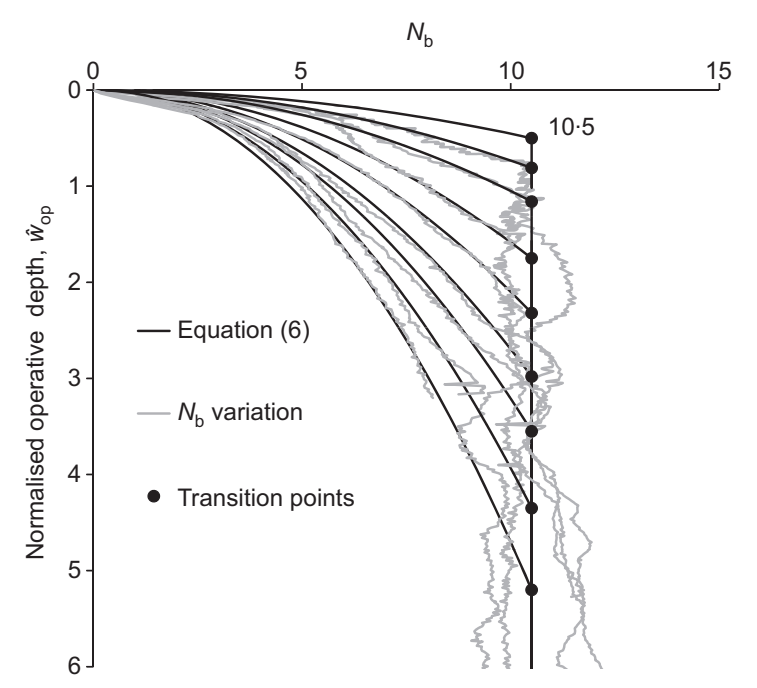

Fig. 7. Measured variation in normalised bearing factor with normalised embedment depth and equation fit 


\section{CONCLUSIONS}

This paper reports on centrifuge tests in which a ball was penetrated into clay under undrained conditions over $s_{\mathrm{u}} / \gamma^{\prime} D=0.07$ to 2.70 (at the transition depth). The depth at which an open cavity, formed by the passage of the ball, closed over is considered to indicate the transitional depth $\hat{w}_{\text {deep-op }}$ where a full flow-round mechanism develops. A novel analytical solution for the soil buoyancy in the case of an open conical hole has been developed. This rigorous approach is necessary to avoid significant errors in the determination of strength during shallow penetration in soils with a low strength to self-weight ratio. For instance, in a clay with zero mudline strength and an undrained shear strength ratio of $s_{\mathrm{u}} / \sigma_{\mathrm{v}}^{\prime}=0 \cdot 25$, the buoyancy resistance increases to almost $70 \%$ of the geotechnical resistance during shallow penetration, and is independent of the penetrometer diameter at all penetration depths. Data from centrifuge experiments, combined with reinterpreted data from LDFE analyses, show a unique relationship between $\hat{w}_{\text {deep-op }}$ and $s_{\mathrm{u}} / \gamma^{\prime} D$ examined over the range $s_{\mathrm{u}} / \gamma^{\prime} D \approx 0 \cdot 1$ to 40 . Equations that describe the change in $\hat{w}_{\text {deep-op }}$ and the capacity factor $N_{\mathrm{b}}$ with $s_{\mathrm{u}} / \gamma^{\prime} D$ are proposed. These equations offer a more rigorous and reliable means of assessing soil strength in the upper few metres of the seabed.

\section{Acknowledgements}

This work forms part of the activities of the Centre for Offshore Foundation Systems (COFS), currently supported as a node of the Australian Research Council Centre of Excellence for Geotechnical Science and Engineering and as a Centre of Excellence by the Lloyd's Register Foundation. The Lloyd's Register Foundation invests in science, engineering and technology for public benefit, worldwide.

\section{REFERENCES}

Chatterjee, S., Randolph, M. F. \& White, D. J. (2012). The effects of penetration rate and strain softening on the vertical penetration resistance of seabed pipelines. Géotechnique 62, No. 7, 573-582.

Chung, S. F. \& Randolph, M. F. (2004). Penetration resistance in soft clay for different shaped penetrometers. Proc. 2nd Int. Conf. on Site Characterisation, Porto 2, No. 1, 671-678.
Cocjin, M. J., Gourvenec, S. M., White, D. J. \& Randolph, M. F. (2014). Tolerably mobile subsea foundations - observations of performance. Géotechnique, in press.

Hossain, M. S., Hu, Y., Randolph, M. F. \& White, D. J. (2005). Limiting cavity depth for spudcan foundations penetrating clay. Géotechnique 55, No. 9, 679-690.

House, A. R., Oliveria, J. R. M. S. \& Randolph, M. F. (2001). Evaluating the coefficient of consolidation using penetration tests. Int. J. Phys. Model. Geotech. 1, No. 3, 17-26.

Hu, P., Stainer, S. A., Cassidy, M. J. \& Wang, D. (2014). Predicting peak resistance of spudcan penetrating sand overlying clay. J. Geotech. Geoenviron. Engng ASCE 140, No. 2 04013009.

Ladd, C. C., Foot, R., Ishihara, K., Schlosser, F. \& Poulos, H. G. (1977). Stress-deformation and strength characteristics. Proc. 9th Int. Conf. Soil Mech. Found. Engng, Tokyo 2, 421-494.

Merifield, R., White, D. J. \& Randolph, M. F. (2009). The effect of surface heave on the response of partially-embedded pipelines on clay. J. Geotech. Geoenviron. Engng ASCE 135, No. 6, 819-829.

Morton, J. P. \& O'Loughlin, C. D. (2012). Dynamic penetration of a sphere in clay. Proc. 7th Int. Conf. on Offshore Site Investigation and Geotechnics, London 7, 223-230.

Puech, A., Orozco-Calderón, M. \& Foray, P. (2010). Mini T-bar testing at shallow penetration. Proc. Frontiers in Offshore Geotechnics, Perth, 305-310.

Randolph, M. F. \& White, D. J. (2008). Pipeline embedment in deep water: processes and quantitative assessment. Proc. Offshore Tech. Conf., Houston 1, 1-16.

Richardson, M. D., O'Loughlin, C. D., Randolph, M. F. \& Gaudin, C. (2009). Setup following installation of dynamic anchors in normally consolidated clay. J. Geotech. Geoenviron. Engng ASCE 135, No. 4, 487-496.

Schofield, A. N. \& Wroth, C. P. (1968). Critical state soil mechanics. London: McGraw-Hill.

Stanier, S. A. \& White, D. J. (2014). Shallow penetrometer penetration resistance. J. Geotech. Geoenviron. Engng ASCE, in press.

Tho, K. K., Leung, C. F., Chow, Y. K. \& Palmer, A. C. (2012). Deep cavity flow mechanism of pipe penetration in clay. Can. Geotech. J. 49, No. 1, 59-69.

White, D. J., Gaudin, C., Boylan, N. \& Zhou, H. (2010). Interpretation of T-bar penetrometer tests at shallow embedment and in very soft soil. Can. Geotech. J. 47, No. 2, 218-229.

Zhou, H., Hossain, M. S., Hu, Y. \& Liu, H. (2013). Behaviour of a ball penetrometer in uniform single and double layer clays. Géotechnique 63, No. 8, 682-694. 